\title{
Predicting the spatial distribution of Biomphalaria straminea, a potential intermediate host for Schistosoma mansoni, in China
}

\author{
Mohamed R. Habib, ${ }^{1,2}$ Yun-Hai Guo, ${ }^{2}$ Shan Lv, ${ }^{2}$ Wen-Biao Gu, ${ }^{2}$ Xiao-Heng Li, ${ }^{3}$ \\ Xiao-Nong Zhou ${ }^{2}$ \\ 'Medical Malacology Laboratory, Theodor Bilharz Research Institute, Giza, Egypt; \\ ${ }^{2}$ National Institute of Parasitic Diseases, Chinese Center for Diseases Control and \\ Prevention, Shanghai; ${ }^{3}$ Shenzhen Center for Disease Control and Prevention, Shenzhen, \\ China
}

\begin{abstract}
Schistosomiasis is one of the most prevalent parasitic diseases impacting human health in the tropics and sub-tropics. The geographic distribution of Schistosoma mansoni, the most widespread species, includes areas in Africa, the Middle East, South America and the Caribbean. Snails of the genus Biomphalaria act as intermediate host for S. mansoni. Biomphalaria straminea is not indigenous in China but was accidentally introduced to Hong Kong from South America and has spread to other habitats in the southern parts of the country. This species is known for its great dispersal capacity that highlights the importance of the snail as a potential host for $S$. mansoni in China. In
\end{abstract}

Correspondence: Xiao-Nong Zhou, National Institute of Parasitic Diseases, Chinese Center for Disease Control and Prevention, 207 Rui Jin Er Road, Shanghai 200025, China.

Tel: +86-21-64738058 - Fax: +86-21-64332670.

E-mail: zhouxn1@chinacdc.cn

Key words: Biomphalaria straminea; Schistosoma mansoni; MaxEnt; Risk map; China.

Acknowledgments: this work was supported by the National Key Research and Development Program of China (2016YFC1202001), and research fund for the prevention and control of technical reserves, National Institute of Parasitic Diseases, Chinese Center for Disease Control and Prevention (CB1603). Mohamed R. Habib was supported by a post-doctoral programme from the Ministry of Science and Technology of China and National Center for International Research on Tropical Diseases (Shanghai, China).

Received for publication: 21 January 2016.

Revision received: 15 September 2016.

Accepted for publication: 16 October 2016.

CC Copyright M.R. Habib et al., 2016

Licensee PAGEPress, Italy

Geospatial Health 2016; 11:453

doi:10.4081/gh.2016.453

This article is distributed under the terms of the Creative Commons Attribution Noncommercial License (CC BY-NC 4.0) which permits any noncommercial use, distribution, and reproduction in any medium, provided the original author(s) and source are credited. this connection, although no such infection has been recorded in the field so far, the continuous expansion of China's projects in endemic areas of Africa and import of the infection via returning workers or visitors deserve attention. The purpose of this study was to map and predict the spatial distribution of $B$. straminea in China. Snail occurrence data were assembled and investigated using MaxEnt software, along with climatic and environmental variables to produce a predictive risk map. Of the environmental variables tested, the precipitation of warmest quarter was the most contribution factor for snail's spatial distribution. Risk areas were found in southeastern China and it is expected that they will guide policies and control programmes to potential areas area of snail abundance and used for spatial targeting of control interventions for this invasive species.

\section{Introduction}

Invasive species have been the focus for many studies in diverse fields such as biology, agriculture, transportation, and economics (Carlton, 1996; Higgins et al., 1999; Kareiva, 1996; Meyerson and Mooney, 2007; Williamson, 1999). Man-derived ecological modification, land reclamation, and movement to new areas resulted in introductions of species to novel landscapes (Peterson, 2003). It is difficult to identify the key factor for successful invasion and colonization that can be employed for a predictive understanding of which species represent potential invaders (Perrins et al., 1993; Peterson, 2003). Instead some climate factors are used to predict the behaviour of invasions based on the concept of ecological niches as a constraint to the distributional potential of species (Grinnell, 1924). Species can only establish populations in areas that meet the ecological requirements found in native areas of these species.

The study of invasive Biomphalaria species acquires an additional importance due to their potential role as intermediate hosts for Schistosoma mansoni that impact human health in tropical and subtropical countries (Basch, 1976; Mandahl-Barth, 1957; Morgan et al., 2001). While factors such as dispersion by floods, plants, aquarium fish shipment, and aquatic birds' migration are linked to the widespread distribution of this intermediate host, other environmental factors regulate their abundance and establishment in new areas. Although these snails can tolerate variations in physical, chemical and biological parameters in the environment where they live (Kloos et al., 2001; Utzinger et al., 1997; Woolhouse, 1992), there is a threshold limit for this tolerance. Several biotic and abiotic factors in the environment control Biomphalaria abundance and distribution (Brown, 1994; 
Rollinson, 2011). Nevertheless, some species of Biomphalaria have proven successful in occupying new ecological niches that in turn led to schistosomiasis expansion, even to non-endemic areas (Sturrock, 1973; Yousif et al., 1996; Lardans and Dissous, 1998; Pointier et al., 2005a; Teodoro et al., 2010).

Biomphalaria straminea is highly invasive, apparently due to its association with aquatic plants trade (Pointier et al., 2005b). It is an important intermediate host for $S$. mansoni transmission in South America especially Brazil (Paraense and Corrêa, 1989; Melo et al., 2006; Fernandez and Thiengo, 2010). Reports of natural infection of this snail species with $S$. mansoni were recorded from different parts of Brazil (Malek, 1985; Fernandez and Thiengo, 2010; Galvão et al., 2010; Barboza et al., 2012). Although it is less important for S. mansoni transmission in areas where its distribution overlaps with $B$. glabrata (Carvalho, 1992), it has been implicated in disease transmission in some Brazilian states, i.e. in Fordlandia in the state of Para (Machado and Martins, 1951) and Goiania in the state of Goias (Cunha, 1967). In addition, its importance in schistosomiasis transmission is linked to its wide distribution in almost all water basins in Brazil especially in the Northeast, south of Bahia and in the northeastern part of the state of Minas Gerais (PAHO, 1968; Paraense et al., 1986). This wide distribution can be attributed to the fact that $B$. straminea has a high capacity to resist periods of drought (Barbosa and Barbosa, 1994). The ability of this snail species to occupy and replace other Biomphalaria species following its introduction proves that it is not only an invasive and competitive species, but also a good colonizer of natural environments (Michelson and Dubois, 1979; Barbosa et al., 2014).

In China, the snail was introduced to Hong Kong in 1974 (MeierBrook, 1974) and subsequently dispersed to different water habitats in Guangdong Province in southern China (Gao et al., 2013; Wang et al., 2013; Attwood et al., 2015). The presence of this species in China and it potential expansion is important from a public health perspective as a potential transmitter of Schistosoma mansoni to mainland China where is only the endemic area for $S$. japonica (Collins et al., 2012; Zhou et al., 2016a). Yet, to date no studies have described the potential distribution of this snail in China.

Although malacological surveys based on manual snail collection are simple and straightforward, they are time-consuming and logistically challenging. A possible alternative way to overcome these challenges is to determine factors that regulate the snail abundance, and use this information to predict its presence in un-surveyed areas (Kristensen $e t$ al., 2001; Stensgaard et al., 2006). Suitable and better models for the distribution and transmission of schistosomiasis can be obtained by integrating the essential biology of the parasite, the intermediate snail host and the definitive human host (Stensgaard et al., 2013). Many studies have demonstrated the relation between environmental and climatic factors and the distribution of Biomphalaria species and prevalence of $S$. mansoni (Woolhouse and Chandiwana, 1989; Bavia et al., 1999; Brooker and Michael, 2000; Kristensen et al., 2001; Malone et al., 2001; Raso et al., 2005; Simoonga et al., 2009; Malone and Bergquist, 2012). Many of these factors are easy to incorporate in a geographical information system (GIS) for the analysis of species suitable habitats and providing estimates of the potential spread of that species (Haltuch et al., 2000; Elith et al., 2006). In addition, data on climate and environment, such as land surface temperature and vegetation indices can easily be obtained from various earth orbiting satellites, and represents a rapid way to develop spatial models of snail distribution (Stensgaard et al., 2005). Prediction maps developed by spatial technologies and species distribution models (SDMs) provide adequate understanding of the potential distribution of various species. Such maps are useful in the management of invasive species (Peterson, 2003; Peterson and
Shaw, 2003).

Different spatial modelling techniques have been used to model Biomphalaria distribution such as maximum entropy (MaxEnt) (Scholte et al., 2012; Stensgaard et al., 2013; Pedersen et al., 2014), genetic algorithm for rule-set prediction (GARP) (Stensgaard et al., 2006), and geostatic indicator Kriging (Guimarães et al., 2009). There are also non-regression models such as the Bayesian geostatistical approach for modelling Biomphalaria spp., distribution (Raso et al., 2005; Vounatsou et al., 2009; Standley et al., 2012; Schur et al., 2013). The data employed in the present study are presence-only data for $B$. straminea in China. These data were used to produce predictive risk maps of the spatial distribution of this potential intermediate host snail using MaxEnt modelling approach using environmental and climatic proxies, obtained from remote sensing (RS) and climate databases, as constraints for the snail distribution. The MaxEnt model is well suited to make predictions from presence only-data, and has been shown to outperform other species distribution modelling software, especially when sample sizes are low (Elith et al., 2006; Phillips et al., 2006; Phillips and Dudík, 2008; Stensgaard et al., 2013). Occurrence-based approaches statistically link spatial data to species distribution records (Elith et al., 2010). The generated maps are useful for the targeting this invasive and potential schistosomiasis snail host for control interventions. The main purpose of this study is to link the distribution of a species to environmental and/or climatic factors to create a prediction map, in order to understand the distribution pattern of the invasive species Biomphalaria in China. (Elith et al., 2006; Zhou et al., 2016b).

\section{Materials and Methods}

\section{Study area and malacological surveys}

Shenzhen City, located in southern China, lies between longitudes $113^{\circ} .46$ and $114^{\circ} .37 \mathrm{E}$ and latitudes $22^{\circ} .27$ and $22^{\circ} .52 \mathrm{~N}$. Shenzhen was selected to build our initial training MaxEnt model because Biomphalaria snails are well established in many water systems of the city. In addition, Shenzhen is adjoining Hong Kong in which the first introduction of $B$. straminea was reported and followed by subsequent dispersal (Meire-Brook, 1974; Attwood et al., 2015). The malacological surveys were conducted during 2015 in many freshwater habitats throughout urban and rural areas of Shenzhen city to map the distribution of $B$. straminea (Figure 1). Sampling was quantified, with two collectors investigating $100 \mathrm{~m}$ length of the water body for 30 minutes and collecting all Biomphalaria found. The snail dip-net with long handle was used for snail collection. Samplings were carried out at different water levels and at least ten dip-nets were taken from each water body. Each location was georeferenced with a handheld geographical positioning systems (GPS) device (Garmin GPSMap 60CS, Garmin Ltd., Kansas City, M0, USA) and the coordinates were recorded. Collected snails were transferred to the laboratory and identified using integrated morphological and molecular approach (Paraense, 1961; Paraense, 1975; Attwood et al., 2015).

\section{Environmental layers}

Environmental data were obtained from different freely accessible remote sensing data sources, as summarised in Table 1. Briefly, climatic data were obtained from Worldclim global dataset (available from: http://www.worldclim.org; Hijmans et al., 2005). These data provide interpolated monthly climatic information from weather stations averaged over a 50-year period (from 1950 to 2000) at the 1-km spatial res- 
olution. The altitude variable was derived from the Hydro-K data set of the United States Geological Survey (USGS) at the same spatial resolution. The bioclimatic variables were selected based on their perceived biological relevance for intermediate host snail distributions (Appleton and Eriksson, 1984; Stensgaard et al., 2013). Also, temperature of the warmest and coldest quarter was included due to the sensitivity of Biomphalaria snails to temperature changes (Appleton, 1977; Pflüger, 1981).

\section{Model implementation}

Distribution modelling was implemented using the MaxEnt approach that is efficient in modelling the potential distributions of species using presence-only datasets (Elith et al., 2011). MaxEnt model estimates niches by finding the distribution of probabilities closest to uniform (maximum entropy), constrained by known observations (i.e. environmental and/or climatic variables) (Phillips et al., 2006). The training model for $B$. straminea distribution in China was built in MaxEnt software version 3.3.3k (https://www.cs.princeton.edu/ schapire/maxent/) using 27 GPS coordinates for Biomphalaria occurrences representing data from the current study, data from the National Institute of Parasitic Diseases (NIPD), Chinese Center for Disease Control and Prevention (CDC), and previously published data (Attwood et al., 2015). Occurrence data were divided into training data, the $75 \%$ of occurrence point data that was used for model prediction and test data, the $25 \%$ of occurrence point data that was used for model validation (Phillips et al., 2006). The model was evaluated using a thresholdindependent index to calculate the area under the receiver operating
Table 1. Environmental and climatic variables used in the regression analysis model to predict the occurrence of Biomphalaria straminea in China.

\begin{tabular}{|c|c|}
\hline Data type & Source \\
\hline Altitude variable at the $1-\mathrm{km}$ resolution & Hydro-K data set (USGS) \\
\hline BIO1 (annual mean temperature) & $\begin{array}{l}\text { Worldclim Global Climate } \\
\text { (http://www.worldclim.org/) }\end{array}$ \\
\hline \multicolumn{2}{|l|}{ BIO2 (mean diurnal range) } \\
\hline \multicolumn{2}{|l|}{$\mathrm{BIO} 3$ (isothermality) } \\
\hline \multicolumn{2}{|l|}{ BIO4 (temperature seasonality) } \\
\hline \multicolumn{2}{|l|}{ BIO5 (max. temperature of warmest month) } \\
\hline \multicolumn{2}{|l|}{ BIO6 (min. temperature of coldest month) } \\
\hline \multicolumn{2}{|l|}{ BIO7 (temperature annual range) } \\
\hline \multicolumn{2}{|l|}{ BIO8 (mean temperature of wettest quarter) } \\
\hline \multicolumn{2}{|l|}{$\mathrm{BIO9}$ (mean temperature of driest quarter) } \\
\hline \multicolumn{2}{|c|}{ BIO10 (mean temperature of warmest quarter) } \\
\hline \multicolumn{2}{|c|}{ BIO11 (mean temperature of coldest quarter) } \\
\hline \multicolumn{2}{|l|}{ BIO12 (annual precipitation) } \\
\hline \multicolumn{2}{|l|}{ BIO13 (precipitation of wettest month) } \\
\hline \multicolumn{2}{|l|}{ BIO14 (precipitation of driest month) } \\
\hline \multicolumn{2}{|l|}{ BIO15 (precipitation seasonality) } \\
\hline \multicolumn{2}{|l|}{ BIO16 (precipitation of wettest quarter) } \\
\hline \multicolumn{2}{|l|}{ BIO17 (precipitation of driest quarter) } \\
\hline \multicolumn{2}{|l|}{ BIO18 (precipitation of warmest quarter) } \\
\hline BIO19 (precipitation of coldest quarter) & \\
\hline
\end{tabular}

USGS, United States Geological Survey (https:/www.usgs.gov/).

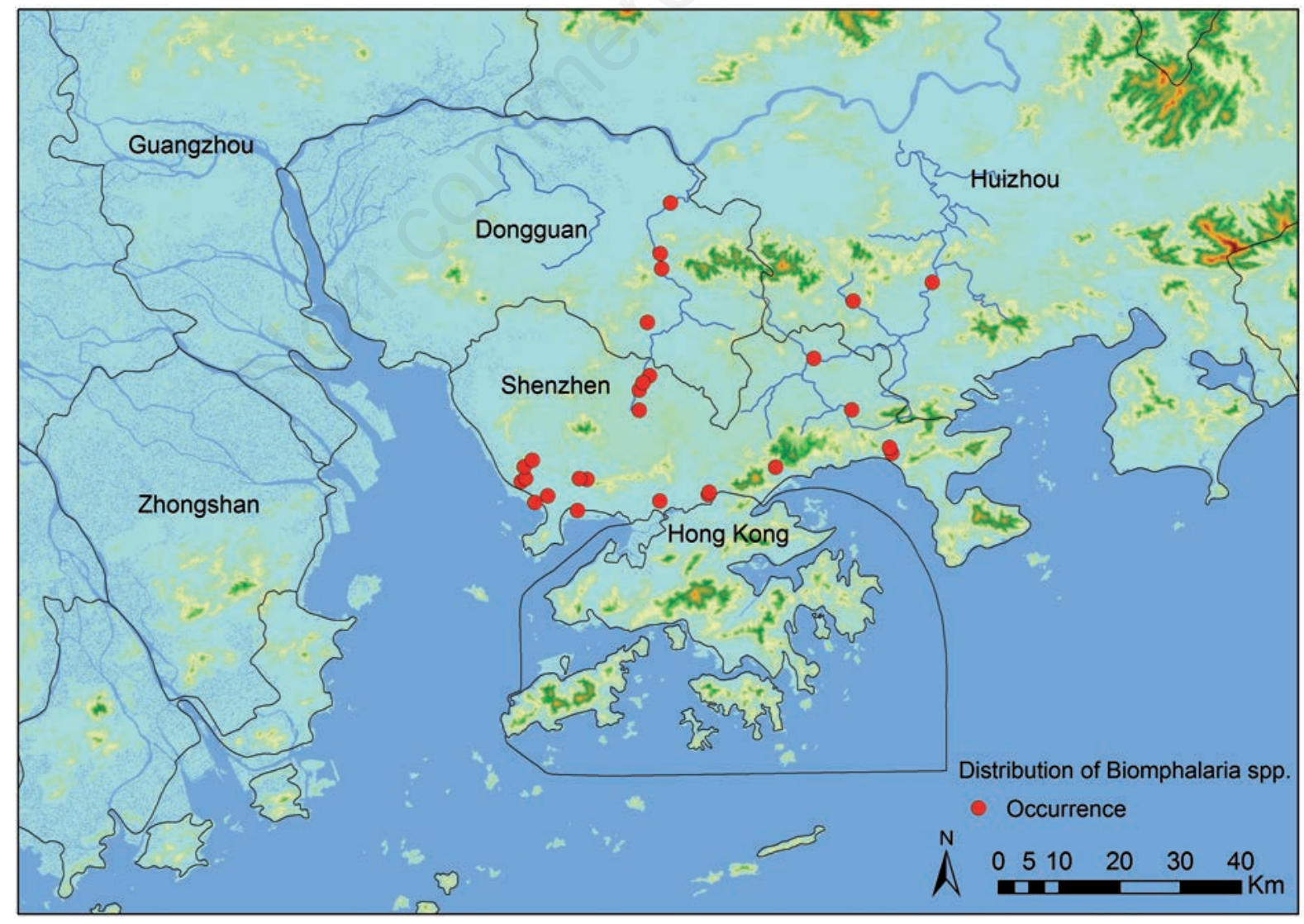

Figure 1. A map showing the locations of Biomphalaria straminea abundance in China. 
characteristic (ROC) curves (AUC), which measures the accuracy of predictive distribution models (Lobo et al., 2008). AUC values near one indicate high predictive performance of the model, while values smaller than 0.5 indicate low model predictive ability (Phillips et al., 2006; Peterson et al., 2008; Phillips and Dudík, 2008). Visualization display was carried out in ArcGIS version 10.1 (ESRI; Redlands, CA, USA). The final models were plotted with a 1-km spatial resolution. The probability of snail presence was expressed as a map layer of habitat suitability on a scale of $0-0.9$ for non-suitable and suitable habitat, respectively.

\section{Results}

\section{Snails habitats}

In Shenzhen, the Biomphalaria habitats were mostly located in urban areas and it included areas of fishing and agricultural activities. The habitats were standing water bodies such as reservoirs, streams, and rivers (Figure 1). Most of locations were typical habitats for snails and all were positive for the presence of Biompharia with variable population densities. B. straminea was collected mostly from lentic sites (flooded furrows and ponds) than from lotic sites (streams and rivers).

\section{Distribution model}

Based on occurrence data for $B$. straminea, we generated a distribution map for the potential areas of snail occurrence in China (Figure 2). The map shows the suitable areas for snail presence. Jackknife analysis (http://www.physics.utah.edu/ detar/ phycs6730/handouts /jackknife/jackknife/) of variables, response curves and percent contributions of variable to the model indicated that, among the environmental and climatic variables used, precipitation of warmest quarter showed the highest contribution to the predictive model (Figure 3).

A full description for the estimates of relative contributions of each environmental variable is presented in Table 2. Percent of contribution was estimated by adding the increase in regularized gain to the contribution of the corresponding variable, or subtracted from it if the change to the absolute value of lambda is negative and randomly permute the values of each environmental variable on training presence and background. The model was re-evaluated on the permuted data, and the resulting AUC is shown in the table, normalized to percentages. While factors such as temperature seasonality, precipitation of driest month, altitude, and mean temperature of wettest quarter were also effective contributors to the model, others such as precipitation seasonality, precipitation of coldest quarter, precipitation of wettest quarter, mean temperature of driest quarter, annual mean temperature, and minimum temperature of coldest month had no contribution to the spatial distribution model.

The possible habitats for $B$. straminea are coded in colours from light green to darker red, representing fewer to greater models. The models suggest that there is a high relative probability of presence, indicating that new, yet un-occupied areas could be suitable habitats for $B$. straminea exist outside the sampled areas; these are mainly distributed in the south of china including Shenzhen and its surrounding areas in Guangdong province, south of Guangxi, and Fujian provinces as well as area outside china such as the North of Taiwan. The logistic threshold

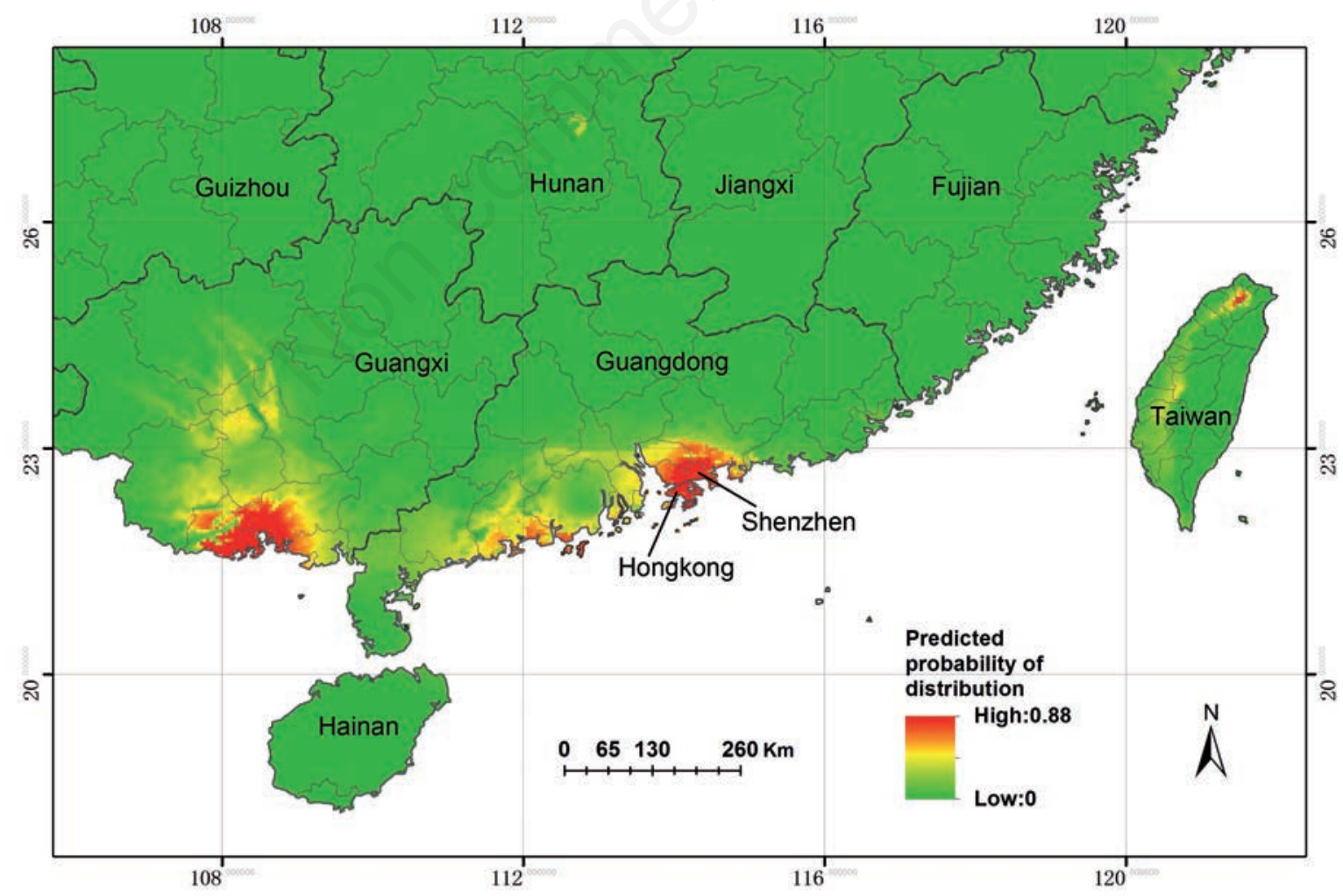

Figure 2. Predicted potential distribution for Biomphalaria straminea using all occurrence records and climatic and environmental variables. Dark red indicates a higher probability of occurrence, while green indicates a low probability of occurrence. 
for the model ranged from 0.010 to 0.396 with an AUC value of 0.99 , indicating a good model performance and high predictive ability.

\section{Discussion}

The present study represents the first predictive map for China with regard to the spatial distribution of $B$. straminea, an invasive species known for its potential ability to transmit $S$. mansoni. A MaxEnt modelling approach was employed to analyze a presence-only dataset for $B$. straminea. The model showed a gradient in suitability for $B$. straminea habitats across southern China ranging from areas of low to high suitability (Figure 2). The MaxEnt output represents the likelihood of natural habitat suitability - or the potential distribution; despite the fact that it does not give the realized distribution of snails in relation to climatic and environmental factors (used as covariates). Our models showed a high predictive accuracy with AUC value above 0.9 , which is a best model-fit category (Phillips and Dudík, 2008).

Previous studies showed that SDMs such as MaxEnt are useful for the identification of environments that can sustain organisms outside their native areas (Phillips et al., 2006). MaxEnt and other SDMs have been applied to study intermediate host distribution (Scholte et al., 2012; Stensgaard et al., 2013; Pedersen et al., 2014). MaxEnt's principle for estimating the distribution of the species is through finding maximum entropy for distribution (the distribution closest to uniform) with the constraints that the expected value of each variable constraint matches its empirical average. The advantage of MaxEnt over other modelling techniques is that it can perform prediction using presenceonly data even with few samples (Phillips et al., 2004). When using presence-only in MaxEnt, the pixels of the study area define the space of MaxEnt probability distribution. The pixels of occurrence recorded constitute the sample points and the responsible features are climatic or other environmental variables (Phillips et al., 2006). In our study, presence-only data describes the occurrences records of $B$. straminea. Although it is advantageous to have the absence data as well, sometimes it is difficult to find these data due to misidentification or inaccessibility at some water bodies. The advantage of using presenceabsence data is that it gives valuable information about surveyed locations (enabling analyses of biases) and prevalence (Phillips et al., 2009). However, sometimes absence data may introduce confounding information because of errors in identifying suitable habitats. Moreover, absence data may be misleading because the species or environment is not at equilibrium (Elith and Leathwick, 2009). SDMs assume that the target species is at equilibrium or close to equilibrium with current environmental conditions (the species has already occupied all suitable habitats and is absent from all unsuitable sites (Guisan and Thuiller, 2005). SDMs also assume that the species' ecological niche is stable in space and time, which mean that it occupied similar environmental conditions as in the native range (Guisan and Zimmermann, 2000). The distribution model could be misleading if the species is missing from locations where climate is actually suitable (areas which can support its establishment following introduction). As a result, spatial models will under- predict potential habitats (Václavík and Meentemeyer, 2012).

Climatic variables such as temperature and precipitation influence species distribution at both global and meso-scales. It is important therefore to carefully select the variables to use for modelling as this will likely influence the degree of model ability to predict presence areas outside the study area or with different environmental conditions (Tambo et al., 2014). This study was capable to provide the precision guideline for the management of invasive species (Peterson and Robins, 2003) and the determinants to predict the impact of climate change on their distribution (Thomas et al., 2004). Climate changes tend to influence the spatial distribution of Biomphalaria with increasing suitable habitats for the snails in the future in addition to the current ones. In our model of prediction, precipitation of warmest quarter

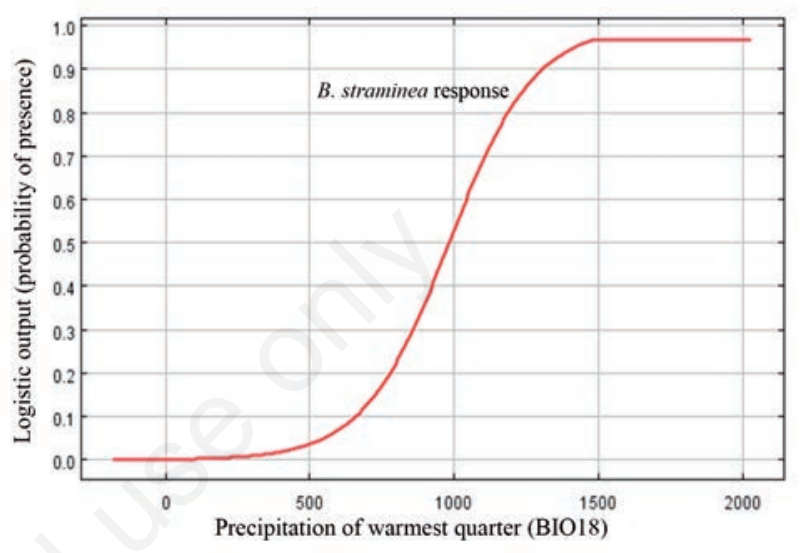

Figure 3. Response curve of Biomphalaria straminea to the climatic variable, precipitation of warmest quarter.

Table 2. Estimates of relative contributions of the environmental variables to the MaxEnt distribution model of Biomphalaria straminea.

\begin{tabular}{lcc}
\hline Environmental variable & $\begin{array}{c}\text { Percent } \\
\text { contribution }\end{array}$ & $\begin{array}{c}\text { Permutation } \\
\text { importance }\end{array}$ \\
Precipitation of warmest quarter & 72.3 & 23.8 \\
Temperature seasonality & 14.4 & 0 \\
\hline Precipitation of driest month & 4 & 0 \\
Altitude & 4 & 0 \\
\hline Mean temperature of wettest quarter & 2.6 & 67.1 \\
Isothermality & 0.9 & 8.3 \\
\hline Precipitation of wettest month & 0.7 & 0.6 \\
Mean temperature of coldest quarter & 0.3 & 0 \\
\hline Mean temperature of warmest quarter & 0.2 & 0 \\
Precipitation of driest quarter & 0.2 & 0 \\
\hline Annual precipitation & 0.1 & 0 \\
Mean diurnal range & 0.1 & 0.1 \\
\hline Maximum temperature of warmest month & 0.1 & 0 \\
Temperature annual range & 0.1 & 0 \\
\hline Precipitation seasonality & 0 & 0.1 \\
Precipitation of coldest quarter & 0 & 0 \\
\hline Precipitation of wettest quarter & 0 & 0 \\
Mean temperature of driest quarter & 0 & 0 \\
\hline Annual mean temperature & 0 & 0 \\
Minimum temperature of coldest month & 0 & 0 \\
\hline
\end{tabular}


was the most contributing climatic factor to the model. Environmental and climatic factors have a variable effect on Biomphalaria spatial distribution depending on the species and geographic areas of occurrence. Both temperature and precipitation were identified as important environmental factors governing the distribution of South American species of Biomphalaria (Scholte et al., 2012). Also, Guimarães et al. (2013) showed that precipitation, minimum temperature, the estimated vegetation index (EVI) and sanitation were positively correlated with $B$. glabratal abundance and consistent with the adequate environmental conditions for the transmission of schistosomiasis. The authors concluded that, the regression models confirmed the importance of the use of environmental variables to characterize the snail habitat in the endemic area of the state of Minas Gerais in Brazil. Bavia et al. (2001) also showed that the distribution of schistosomiasis in Bahia, at municipalities level, is related to the vegetation index (NDVI) and temperature using low-resolution sensor data such as the advanced very high-resolution radiometer (AVHRR). Table 3 reviews some of the spatial technologies used to study the distribution of $B$. straminea in South America and the most contributing climatic or environmental factors to the distribution model.

In the case of African species Biomphalaria, most of the SDMs studies indicated that warmer climate is expected to minimize the range of snails distribution (Stensgaard et al., 2013). NDVI and day temperatures values were also found to govern $B$. pfeifferi and $B$. sudanica distribution and $S$. mansoni transmission in Uganda (Stensgaard et al., 2005). Moreover, Pedersen et al. (2014) showed that temperature play an important role in B. pfeifferi potential distribution in Zimbabwe and indicated that climate change may significantly alter the future spatial distribution of this snail species. Also, NDVI and maximum temperature were important factors determining the spatial distribution of $B$. pfeifferi in Ethiopia (Malone et al., 2001). Although SDMs based on the temporal climate have similar accuracy to realistic models (Hijmans and Graham, 2006), it is difficult to measure accuracy under future climate conditions. SDMs approaches do not include any physiological information about invasive species or their mode of spread and competition with local species. These approaches depend on empirical data and can thus be judged as more trustworthy because correlation between climate and distribution does not necessarily imply a causal relationship between climate and distribution (Dormann, 2007). However, there is a high degree of correlation among environmental variables and the best predictors of species distribution may therefore be hidden and different from the ones governing species establishment. In the current study, for example, precipitation of warmest quarter was the most contributing environmental factor for $B$. straminea distribution model although this snail species is known as droughtresistant. There is thus a complication in the modelling of invasive species because they do not simply follow the factors regulating their abundance in their native range. Instead, they can undergo adaptive evolution to the new environmental condition in the newly invaded areas (Huey et al., 2005; Colwell and Rangel, 2009).

A thorough understanding the biology of possible hosts of schistosomiasis is necessary for any control strategy. In this respect, the current study is a critical addition to the tools needed to efficiently manage surveillance, control the potential intermediate host, $B$. straminea and prevent schistosomiasis transmission to mainland China. Although there are no records for the implication of $B$. straminea in $S$. mansoni transmission in China so far, the current model of snail distribution merits further attention in view of the increased number of schistosomiasis mansoni infected Chinese returning from endemic areas in Africa, as well as the possibility of introduction of infected snails in a similar way to what resulted in the current colonization of $B$. straminea in southern China (Wang et al., 2013). Moreover, the ability of B. straminea to tolerate hypertrophic conditions increases its potential for spread to organically polluted sites involving human activity. There is thus a clear risk for the establishment of $S$. mansoni-infected foci with functional transmission if the parasite were also introduced (Yipp, 1990). Spatial technologies have been extensively used to study vector distribution and parasite prevalence with relevance for medical and veterinary medicine, encouraging studies of the potential impact of climate change and revealing the spatial and climatic parameters which determine the distribution limits of diseases at various scales (Lobitz et al., 2000; Tanser et al., 2003; Rogers and Randolph, 2006; Malone and Bergquist,

Table 3. Review of spatial techniques used to study the spatial distribution of Biomphalaria straminea in Brazil.

\begin{tabular}{|c|c|c|c|}
\hline Satellite sensor & Effective covariates & Procedure/technique & Reference \\
\hline- & $\begin{array}{l}\text { Population density and the duration } \\
\text { of the annual dry period }\end{array}$ & GIS/intergraph $\mathrm{MGE}^{\circ}$ & Bavia et al. (1999) \\
\hline AVHRR & NDVI; $\mathrm{d} T$ & GIS/SPRING ${ }^{\#}$ modular GIS software & Bavia et al. (2001) \\
\hline- & Rainfall & Differential global positioning systems (DGPS) ${ }^{\S}$ and GIS software & Kloos et al. (2001) \\
\hline MODIS; SRTM & $\mathrm{TN}_{\mathrm{s}} ; \mathrm{NDVI}_{\mathrm{w}}$ & Multiple linear regression/GIS & Guimarães et al. (2008) \\
\hline- & - & $\begin{array}{l}\text { Geostatic indicator Kriging/SPRING } \\
\text { (georeferenced information } \\
\text { processingsystem) }\end{array}$ & Guimarães et al. (2009) \\
\hline- & Rainfall & GPS/ArcGis 9.3 (ESRI software) ${ }^{\wedge}$ & Galvão et al. (2010) \\
\hline- & $\begin{array}{l}\text { Annual precipitation; } \\
\text { temperature seasonality; } \\
\text { temperature annual range }\end{array}$ & Maximum entropy/MaxEnt & Scholte et al. (2012) \\
\hline- & - & GIS in ArcGIS 10.0 (ESRI software) ${ }^{\wedge}$ & Barbosa et al. (2013) \\
\hline- & - & GIS/TerraView 4.1.0\$ & Barbosa et al. (2014) \\
\hline
\end{tabular}

GIS, geographical information system; MGE, modular geographic environment; AVHRR, advanced very high resolution radiometer; NDVI, normalised difference vegetation index; dT, average diurnal temperature differences; MODIS, moderate resolution imaging spectroradiometer; SRTM, shuttle radar topography mission; TNs, summer minimum temperature; NDVI N $_{w}$, winter normalized difference vegetation index. ${ }^{\circ}$ http://www.grsgis.com/mgemga.html; " a freeware GIS and remote sensing image processing system; ${ }^{\$}$ http://www.esri.com/news/arcuser/0103/differentiallof2.html; ^ http:/www.esri.com/software/arcgis; ${ }^{\$}$ http://www.dpi.inpe.br/terraview_eng/index.php 
2012). According to King et al. (2006), the next generation of schistosomiasis control will largely depend on using new monitoring tools and effective transmission containment including statistical ecological modelling that would include spatial technologies.

\section{Conclusions}

The results presented here show that there may be potential for $B$. straminea to disperse further in China as the mode here indicates large suitable habitats in areas around its current distribution. The results also confirm the important role played by climatic factors in regulating freshwater snail distributions and indicate the usefulness of Worldclim databases in SDMs. Although the predictive map obtained by MaxEnt seems efficient in analysing and predicting presence-only data for understanding geographical and ecological distributions of this snail species, comparisons with other SDMs are also needed. The obtained risk map for $B$. straminea distribution in China can be used to inform proper public health strategies, guiding fieldwork in places with higher occurrence probability of the new invasion of a potential intermediate host species for $S$. mansoni in China. The map might be used as predictor for potential $S$. mansoni distribution in case of any accidental introduction of the parasite to areas harbouring this snail. Since the presence of the intermediate host snails of $S$. mansoni is a proxy for the disease distribution, the risk map can guide spatial targeting of control interventions.

\section{References}

Appleton C, 1977. The influence of temperature on the life-cycle and distribution of Biomphalaria pfeifferi (Krauss, 1948) in SouthEastern Africa. Int J Parasitol 7:335-45.

Appleton C, Eriksson IM, 1984. The influence of fluctuating above-optimal temperature regimes on the fecundity of Biomphalaria pfeifferi (Mollusca: Planorbidae). T Roy Soc Trop Med Hyg 78:49-54.

Attwood SW, Huo GN, Qiu JW, 2015. Update on the distribution and phylogenetics of Biomphalaria (Gastropoda: Planorbidae) populations in Guangdong Province, China. Acta Trop 141:258-70.

Barbosa CS, Barbosa VS, Melo FLd, Melo MSBd, Bezerra L, Campos JV, Rodrigues BX, Nascimento WCd, Gomes ES, Leal-Neto 0, 2013. Autochthonous cases of schistosomiasis in children in Recife, Northeastern Brazil. Rev Saúde Pública 47:684-90.

Barbosa CS, Barbosa VS, Nascimento WC, Pieri OS, Araújo KC, 2014. Study of the snail intermediate hosts for Schistosoma mansoni on Itamaracá Island in northeast Brazil: spatial displacement of Biomphalaria glabrata by Biomphalaria straminea. Geospat Health 8:345-51.

Barbosa FS, Barbosa CS, 1994. The bioecology of snail vectors for schitosomiasis in Brazil. Cad Saúde Pública 10:200-9.

Barboza DM, Zhang C, Santos NC, Silva MMBL, Rollemberg CVV, de Amorim FJR, Ueta MT, de Melo CM, de Almeida JAP, Jeraldo VdLS, 2012. Biomphalaria species distribution and its effect on human Schistosoma mansoni infection in an irrigated area used for rice cultivation in northeast Brazil. Geospat Health 6:103-9.

Basch PF, 1976. Intermediate host specificity in Schistosoma mansoni. Exp Parasitol 39:150-69.

Bavia M, Malone J, Hale L, Dantas A, Marroni L, Reis R, 2001. Use of thermal and vegetation index data from earth observing satellites to evaluate the risk of schistosomiasis in Bahia, Brazil. Acta Trop 79:79-85.

Bavia ME, Hale LF, Malone JB, Braud DH, Shane SM, 1999. Geographic information systems and the environmental risk of schistosomiasis in Bahia, Brazil. Am J Trop Med Hyg 60:566-72.

Brooker S, Michael E, 2000. The potential of geographical information systems and remote sensing in the epidemiology and control of human helminth infections. Adv Parasitol 47:245-88.

Brown D, 1994. Freshwater snails of Africa and their medical importance. Taylor and Francis, London, UK.

Carlton JT, 1996. Biological invasions and cryptogenic species. Ecology 77:1653-5.

Carvalho OdS, 1992. Intermediate hosts of Schistosoma mansoni in Brazil. Mem I Oswaldo Cruz 87:307-9.

Collins C, Xu J, Tang S, 2012. Schistosomiasis control and the health system in P.R. China. Infect Dis Poverty 1:8.

Colwell RK, Rangel TF, 2009. Hutchinson's duality: the once and future niche. P Natl Acad Sci USA 106:19651-8.

Cunha NA, 1967. [Primeiros focos de esquistossomose mansônica em Goiânia, Estado de Goiás, Brasil]. [Article in Brazilian]. Rev I Med Trop S Paulo 9:357-8.

Dormann CF, 2007. Effects of incorporating spatial autocorrelation into the analysis of species distribution data. Global Ecol Biogeograph 16:129-38.

Elith J, Graham CH, Anderson RP, Dudik M, Ferrier S, Guisan A, Hijmans RJ, Huettmann F, Leathwick JR, Lehmann A, Li J, Lohmann LG, Loiselle BA, Manion G, Moritz C, Nakamura M, Nakazawa Y, Overton JMcC, Peterson AT, Phillips SJ, Richardson KS, Scachetti-Pereira R, Schapire RE, Soberòn J, Williams S, Wisz MS, Zimmermann NE, 2006. Novel methods improve prediction of species' distributions from occurrence data. Ecography 29:129-51.

Elith J, Kearney M, Phillips S, 2010. The art of modelling range shifting species. Methods Ecol Evol 1:330-42.

Elith J, Leathwick JR, 2009. Species distribution models: ecological explanation and prediction across space and time. Annu Rev Ecol Evol Syst 40:677.

Elith J, Phillips SJ, Hastie T, Dudík M, Chee YE, Yates CJ, 2011. A statistical explanation of MaxEnt for ecologists. Divers Distrib 17:4357.

Fernandez MA, Thiengo SC, 2010. Susceptibility of Biomphalaria straminea from Peixe Angical dam, Tocantins, Brazil to infection with three strains of Schistosoma mansoni. Mem I Oswaldo Cruz 105:488-91.

Galvão AF, Favre TC, Guimarães RJ, Pereira AP, Zani LC, Felipe KT, Domingues ALC, Carvalho OS, Barbosa CS, Pieri OS, 2010. Spatial distribution of Schistosoma mansoni infection before and after chemotherapy with two praziquantel doses in a community of Pernambuco, Brazil. Mem I 0swaldo Cruz 105:555-62.

Gao S, Li X, Huang S, Xie X, Mei S, Ruan C, Huang D, 2013. Primary investigation of distribution and ecological environment of Biomphalaria straminea in Dasha and Guanlan Rivers in Shenzhen areas. Chin Trop Med 13:313-7.

Grinnell J, 1924. Geography and evolution. Ecology 5:225-9.

Guimarães RJ, Freitas CC, Dutra LV, Felgueiras CA, Moura AC, Amaral RS, Drummond SC, Scholte RG, Oliveira G, Carvalho OS, 2009. Spatial distribution of Biomphalaria mollusks at São Francisco River Basin, Minas Gerais, Brazil, using geostatistical procedures. Acta Trop 109:181-6.

Guimarães RJ, Freitas CC, Dutra LV, Moura AC, Amaral RS, Drummond SC, Scholte RG, Carvalho OS, 2008. Schistosomiasis risk estimation in Minas Gerais state, Brazil, using environmental data and 
GIS techniques. Acta Trop 108:234-41.

Guimarães RJ, Freitas CC, Oliveira G, Dutra LV, Carvalho OS, 2013. Multiple regression for the schistosomiasis positivity index estimates in the Minas Gerais State-Brazil at small communities and cities levels. INTECH Open Access Publisher, Rijeka, Croatia.

Guisan A, Thuiller W, 2005. Predicting species distribution: offering more than simple habitat models. Ecol Lett 8:993-1009.

Guisan A, Zimmermann NE, 2000. Predictive habitat distribution models in ecology. Ecol Modell 35:147-86.

Haltuch MA, Berkman PA, Garton DW, 2000. Geographic information system (GIS) analysis of ecosystem invasion: exotic mussels in Lake Erie. Limnol Oceanogr 45:1778-87.

Higgins SI, Richardson DM, Cowling RM, Trinder Smith TH, 1999. Predicting the landscape scale distribution of alien plants and their threat to plant diversity. Conserv Biol 13:303-13.

Hijmans RJ, Cameron SE, Parra JL, Jones PG, Jarvis A, 2005. Very high resolution interpolated climate surfaces for global land areas. Int $\mathrm{J}$ Climatol 25:1965-78.

Hijmans RJ, Graham CH, 2006. The ability of climate envelope models to predict the effect of climate change on species distributions. Global Change Biol 12:2272-81.

Huey RB, Gilchrist GW, Hendry AP, 2005. Using invasive species to study evolution. Species invasions: insights. Ecol Evol Biogeogr 1:139-64.

Kareiva P, 1996. Developing a predictive ecology for non-indigenous species and ecological invasions. Ecology 77:1651.

King CH, Sturrock RF, Kariuki HC, Hamburger J, 2006. Transmission control for schistosomiasis - why it matters now. Trend Parasitol 22:575-82.

Kloos H, Souza Cd, Gazzinelli A, Soares Filho BS, Temba PdC, Bethony J, Page K, Grzywacz C, Lewis F, Minchella D, 2001. The distribution of Biomphalaria spp. in different habitats in relation to physical, biological, water contact and cognitive factors in a rural area in Minas Gerais, Brazil. Mem I Oswaldo Cruz 96:57-66.

Kristensen T, Malone J, McCarroll J, 2001. Use of satellite remote sensing and geographic information systems to model the distribution and abundance of snail intermediate hosts in Africa: a preliminary model for Biomphalaria pfeifferi in Ethiopia. Acta Trop 79:73-8.

Lardans V, Dissous C, 1998. Snail control strategies for reduction of schistosomiasis transmission. Parasitol Today 14:413-7.

Lobitz B, Beck L, Huq A, Wood B, Fuchs G, Faruque A, Colwell R, 2000. Climate and infectious disease: use of remote sensing for detection of Vibrio cholerae by indirect measurement. P Natl Acad Sci USA 97:1438-43.

Lobo JM, Jiménez Valverde A, Real R, 2008. AUC: a misleading measure of the performance of predictive distribution models. Global Ecol Biogeogr 17:145-51.

Machado W, Martins C, 1951. [Um foco autóctone de Schistosomose no Pará]. [Article in Brazilian]. Hospital 39:289-90.

Malek EA, 1985. Snail hosts of schistosomiasis and other snail-transmitted diseases in tropical America: a manual. Pan American Health Organization, Regional Office of the World Health Organization, Washington, DC, USA.

Malone J, Yilma J, McCarroll J, Erko B, Mukaratirwa S, Zhou X, 2001. Satellite climatology and the environmental risk of Schistosoma mansoni in Ethiopia and east Africa. Acta Trop 79:59-72.

Malone JB, Bergquist NR, 2012. Mapping and modelling neglected tropical diseases and poverty in Latin America and the Caribbean. Geospat Health 6:1-5.

Mandahl-Barth G, 1957. Intermediate hosts of Schistosoma: African Biomphalaria and Bulinus: 2. B World Health Organ 17:1.
Meier-Brook C, 1974. A snail intermediate host of Schistosoma mansoni introduced into Hong Kong. B World Health Organ 51:661.

Melo FL, do Vale Gomes AL, Barbosa CS, Werkhauser RP, Abath FG, 2006. Development of molecular approaches for the identification of transmission sites of schistosomiasis. T Roy Soc Trop Med Hyg 100:1049-55.

Meyerson LA, Mooney HA, 2007. Invasive alien species in an era of globalization. Front Ecol Environ 5:199-208.

Michelson E, Dubois L, 1979. Competitive interaction between two snail hosts of Schistosoma mansoni: laboratory studies on Biomphalaria glabrata and B. straminea. Rev I Med Trop São Paulo 21:246.

Morgan J, Dejong R, Snyder S, Mkoji G, Loker E, 2001. Schistosoma mansoni and Biomphalaria: past history and future trends. Parasitology 123:211-28.

PAHO, 1968. A guide for the identification of the snail intermediate hosts of schistosomiasis in the Americas. Pan American Health Organization, Regional Office of the World Health Organization, Washington, DC, USA.

Paraense W, 1975. Biomphalaria orbignyi sp. n. from Argentina (Gastropoda: Basommatophora: Planorbidae). Rev Brasil Biol 35:211-22.

Paraense W, Reis F, Faria I, Katz N, 1986. [Distribuição dos caramujos no Brasil. Modernos conhecimentos sobre esquistossomose mansônica]. [Book in Brazilian]. Biblioteca da Academia Mineira de Medicina, Belo Horizonte, Brazil.

Paraense WL, 1961. The nomenclature of Brazilian planorbids. II. Australorbis tenagophilus (Orbigny, 1835). Rev Bras Biol 21:343.

Paraense WL, Corrêa LR, 1989. A potential vector of Schistosoma mansoni in Uruguay. Mem I Oswaldo Cruz 84:281-8.

Pedersen UB, Midzi N, Mduluza T, Soko W, Stensgaard A-S, Vennervald BJ, Mukaratirwa S, Kristensen TK, 2014. Modelling spatial distribution of snails transmitting parasitic worms with importance to human and animal health and analysis of distributional changes in relation to climate. Geospat Health 8:335-51.

Perrins J, Fitter A, Williamson M, 1993. Population biology and rates of invasion of three introduced Impatiens species in the British Isles. J Biogeogr 33-44.

Peterson AT, 2003. Predicting the geography of species' invasions via ecological niche modeling. Quart Rev Biol 78:419-33.

Peterson AT, Pape M, Soberón J, 2008. Rethinking receiver operating characteristic analysis applications in ecological niche modeling. Ecol Model 213:63-72.

Peterson AT, Robins CR, 2003. Using ecological niche modeling to predict barred owl invasions with implications for spotted owl conservation. Conserv Biol 17:1161-5.

Peterson AT, Shaw J, 2003. Lutzomyia vectors for cutaneous leishmaniasis in Southern Brazil: ecological niche models, predicted geographic distributions, and climate change effects. Int J Parasitol 33:919-31.

Pflüger W, 1981. Experimental epidemiology of schistosomiasis. Z Parasit 66:221-9.

Phillips SJ, Anderson RP, Schapire RE, 2006. Maximum entropy modeling of species geographic distributions. Ecol Model 190:231-59.

Phillips SJ, Dudík M, 2008. Modeling of species distributions with Maxent: new extensions and a comprehensive evaluation. Ecography 31:161-75.

Phillips SJ, Dudík M, Elith J, Graham CH, Lehmann A, Leathwick J, Ferrier S, 2009. Sample selection bias and presence-only distribution models: implications for background and pseudo-absence data. Ecol Appl 19:181-97. 
Phillips SJ, Dudík M, Schapire RE, 2004. A maximum entropy approach to species distribution modelling. Proceedings of the 21st International Conference on Machine Learning, Banff, Canada, 2004.

Pointier J, David P, Jarne P, 2005a. Biological invasions: the case of planorbid snails. J Helminthol 79:249-56.

Pointier J-P, DeJong R, Tchuenté LT, Kristensen T, Loker E, 2005b. A neotropical snail host of Schistosoma mansoni introduced into Africa and consequences for the schistosomiasis transmission: Biomphalaria tenagophila in Kinshasa (Democratic Republic of Congo). Acta Trop 93:191-9.

Raso G, Matthys B, N'goran E, Tanner M, Vounatsou P, Utzinger J, 2005. Spatial risk prediction and mapping of Schistosoma mansoni infections among schoolchildren living in western Côte d'Ivoire. Parasitology 131:97-108.

Rogers D, Randolph S, 2006. Climate change and vector-borne diseases. Adv Parasitol 62:345-81.

Rollinson D, 2011. Biomphalaria: natural history, ecology and schistosome transmission. Biomphalaria snails and larval trematodes. Springer, Amsterdam, The Netherlands.

Scholte RG, Carvalho OS, Malone JB, Utzinger J, Vounatsou P, 2012. Spatial distribution of Biomphalaria spp., the intermediate host snails of Schistosoma mansoni, in Brazil. Geospat Health 6:95-101.

Schur N, Hürlimann E, Stensgaard A-S, Chimfwembe K, Mushinge G, Simoonga C, Kabatereine NB, Kristensen TK, Utzinger J, Vounatsou P, 2013. Spatially explicit Schistosoma infection risk in eastern Africa using Bayesian geostatistical modelling. Acta Trop 128:365-77.

Simoonga C, Utzinger J, Brooker S, Vounatsou P, Appleton C, Stensgaard A-S, Olsen A, Kristensen TK, 2009. Remote sensing, geographical information system and spatial analysis for schistosomiasis epidemiology and ecology in Africa. Parasitology 136:168393.

Standley CJ, Vounatsou P, Gosoniu L, Jørgensen A, Adriko M, Lwambo NJ, Lange CN, Kabatereine NB, Stothard JR, 2012. The distribution of Biomphalaria (Gastropoda: Planorbidae) in Lake Victoria with ecological and spatial predictions using Bayesian modelling. Hydrobiologia 683:249-64.

Stensgaard A, Jorgensen A, Kabatareine N, Malone J, Kristensen T, 2005. Modeling the distribution of Schistosoma mansoni and host snails in Uganda using satellite sensor data and geographical information systems. Parassitologia 47:115.

Stensgaard A-S, Jørgensen A, Kabatereine NB, Rahbek C, Kristensen TK, 2006. Modeling freshwater snail habitat suitability and areas of potential snail-borne disease transmission in Uganda. Geospat Health 1:93-104.

Stensgaard A-S, Utzinger J, Vounatsou P, Hürlimann E, Schur N, Saarnak CF, Simoonga C, Mubita P, Kabatereine NB, Tchuenté LAT, 2013. Large-scale determinants of intestinal schistosomiasis and intermediate host snail distribution across Africa: does climate matter? Acta Trop 128:378-90.

Sturrock R, 1973. Field studies on the transmission of Schistosoma mansoni and on the bionomics of its intermediate host, Biomphalaria glabrata, on St. Lucia, West Indies. Int J Parasitol 3:175-94.

Tambo E, Ai L, Zhou X, Chen JH, Hu W, Bergquist R, Guo JG, Utzinger J, Tanner M, Zhou XN, 2014. Surveillance-response systems: the key to elimination of tropical diseases. Infect Dis Poverty 3:17.

Tanser FC, Sharp B, Le Sueur D, 2003. Potential effect of climate change on malaria transmission in Africa. Lancet 362:1792-8.

Teodoro TM, Janotti-Passos LK, dos Santos Carvalho 0, Caldeira RL, 2010. Occurrence of Biomphalaria cousini (Mollusca: Gastropoda) in Brazil and its susceptibility to Schistosoma mansoni (Platyhelminths: Trematoda). Mol Phylog Evol 57:144-51.

Thomas CD, Cameron A, Green RE, Bakkenes M, Beaumont LJ, Collingham YC, Erasmus BF, De Siqueira MF, Grainger A, Hannah L, 2004. Extinction risk from climate change. Nature 427:145-8.

Utzinger J, Mayombana C, Mez K, Tanner M, 1997. Evaluation of chemical and physical-morphological factors as potential determinants of Biomphalaria pfeifferi (Krauss, 1848) distribution. Mem I Oswaldo Cruz 92:323-8.

Václavík T, Meentemeyer RK, 2012. Equilibrium or not? Modelling potential distribution of invasive species in different stages of invasion. Divers Distrib 18:73-83.

Vounatsou P, Raso G, Tanner M, N'goran E, Utzinger J, 2009. Bayesian geostatistical modelling for mapping schistosomiasis transmission. Parasitology 136:1695-705.

Wang W, Liang YS, Hong QB, Dai JR, 2013. African schistosomiasis in mainland China: risk of transmission and countermeasures to tackle the risk. Parasite Vector 6:249.

Williamson M, 1999. Invasions. Ecography 22:5-12.

Woolhouse M, 1992. Population biology of the freshwater snail Biomphalaria pfeifferi in the Zimbabwe. J Appl Ecol 29:687-94.

Woolhouse M, Chandiwana S, 1989. Spatial and temporal heterogeneity in the population dynamics of Bulinus globosus and Biomphalaria pfeifferi and in the epidemiology of their infection with schistosomes. Parasitology 98:21-34.

Yipp MW, 1990. Distribution of the schistosome vector snail, Biomphalaria straminea (Pulmonata: Planorbidae) in Hong Kong. J Moll Stud 56:47-55.

Yousif F, Haroun N, Ibrahim A, El-Bardicy S, 1996. Biomphalaria glabrata: a new threat for schistosomiasis transmission in Egypt. J Egypt Soc Parasitol 26:191-205.

Zhou X, Yap P, Tanner M, Bergquist R, Utzinger J, Zhou XN, 2016a. Surveillance and response systems for elimination of tropical diseases: summary of a thematic series in infectious diseases of poverty. Infect Dis Poverty 5:49.

Zhou YB, Liang S, Chen Y, Jiang QW, 2016b. The three gorges dam: does it accelerate or delay the progress towards eliminating transmission of schistosomiasis in China? Infect Dis Poverty 5:63. 